Regular paper

\title{
A new wideband planar antenna with band-notch functionality at GPS, Bluetooth and WiFi bands for integration in portable wireless systems
}

\author{
Mohammad Alibakhshikenari ${ }^{\mathrm{a}, *}$, Ernesto Limiti $^{\mathrm{a}}$, Mohammad Naser-Moghadasi ${ }^{\mathrm{b}}$, Bal S. Virdee ${ }^{\mathrm{c}}$ \\ R.A. Sadeghzadeh ${ }^{\mathrm{d}}$ \\ a Dipartimento di Ingegneria Elettronica, Università degli Studi di Roma “Tor Vergata”, Via del Politecnico 1, 00133 Roma, Italy \\ ${ }^{\mathrm{b}}$ Faculty of Engineering, Science and Research Branch, Islamic Azad University, Tehran, Iran \\ ${ }^{c}$ London Metropolitan University, Center for Communications Technology, Faculty of Life Sciences and Computing, London N7 8DB, UK \\ ${ }^{\mathrm{d}}$ Faculty of Electrical and Computer Engineering, K. N. Toosi University of Technology, Tehran, Iran
}

\section{A R T I C L E I N F O}

Article history:

Received 15 October 2016

Accepted 27 November 2016

\section{Keywords:}

Wideband antenna

Notch bands

Planar antennas

Microstrip technology

GPS

Bluetooth

WiFi

Portable wireless systems

\begin{abstract}
A B S T R A C T
Empirical results are presented for a novel miniature planar antenna that operates over a wide bandwidth ( $500 \mathrm{MHz}$ to $3.05 \mathrm{G} \mathrm{Hz}$ ). The antenna consists of dual-square radiating patches separated by two narrow vertical stubs to reject interferences from GPS, Bluetooth and WiFi bands. Radiating patches and stubs are surrounded by a ground-plane conductor, and the antenna is fed through a common coplanar waveguide transmission line (CPW-TL). The two vertical stubs generate pass-band resonances enabling wideband operation across the following communications standards: cellular, APMS, JCDMA, GSM, DCS, PCS, KPCS, IMT-2000, WCDMA, UMTS and WiMAX. Embedded in the ground-plane conductor is an $\mathrm{H}$-shaped dielectric slit, which has been rotated by $90^{\circ}$, whose function is to reject interferences from GPS, Bluetooth and WiFi bands. Measurements results confirm the antenna exhibits notched characteristics at frequency bands of GPS (1574.4-1576.4 MHz), Bluetooth (2402-2480 MHz) and WiFi (2412$2483.5 \mathrm{MHz}$ ). The impedance bandwidth of the antenna is $2.55 \mathrm{G} \mathrm{Hz}$ for VSWR $<2$, which corresponds to a fractional bandwidth of $143.66 \%$. Measured results also confirm that the antenna radiates omnidirectionally in the E-plane with appreciable gain performance over its operating frequency range. The antenna has dimensions of $15 \times 15 \times 0.8 \mathrm{~mm}^{3}$.
\end{abstract}

(c) 2016 Elsevier GmbH. All rights reserved.

\section{Introduction}

Recently, broadband technology has attracted great attention for wireless applications as it offers advantages of high speed data rate, low power consumption, high capacity, low cost, and low complexity [1-3]. Broadband systems necessitate the use of broadband antennas with desirable features including small physical size, ease of manufacture using conventional fabrication technologies, gain and omnidirectional radiation characteristics. Several broadband antenna designs have been recently developed [4-16]; such designs include planar monopole antennas that promise wideband performance for wireless communication systems. Wideband systems however will need to operate and coexist with narrowband communication systems such as Global Position System (GPS) (1574.4-1576.4 MHz), Bluetooth (2402-2480 MHz)

\footnotetext{
* Corresponding author.

E-mail addresses: Alibakhshikenari@ing.uniroma2.it (M. Alibakhshikenari), limiti@ing.uniroma2.it (E. Limiti), mn.moghaddasi@srbiau.ac.ir (M. Naser-Moghadasi), b.virdee@londonmet.ac.uk (B.S. Virdee), sadeghz@eetd.kntu.ac.ir (R.A. Sadeghzadeh).
}

and WiFi (2412-2483.5 MHz). The abovementioned narrowband systems are a source of severe electromagnetic interference to the operation of wideband systems. It is therefore highly desirable to design the broadband antenna with integral band-notched functionality in order to mitigate any interference. Extensive investigations have been carried out to design wideband antennas with notch bands without using stop band filters [17-19]. Various techniques have been adopted to incorporate band-notched functionality in wideband antennas, including embedding in the radiator and ground-plane the use of slits of different shapes and sizes [20-23]. Hence, a common way to create single or dual notch bands in wideband systems is to add resonant elements to the antenna that includes loading the antenna with slots of various shapes, i.e. L-shaped slots [24], U-shaped slots [25], C-shaped slot [26], W-shaped slot [27] and H-shaped slot [28]. In [29,30], the authors have used split-ring resonators (SRR) in the antenna structure to create notch bands. It is shown in [31] that rejection bands can also be created by adding multiple $U$-shaped slots in a log periodic dipole antenna. In $[32,33]$ the authors have placed a modified a U-slot on a planar plate monopole antenna to create notch bands. 


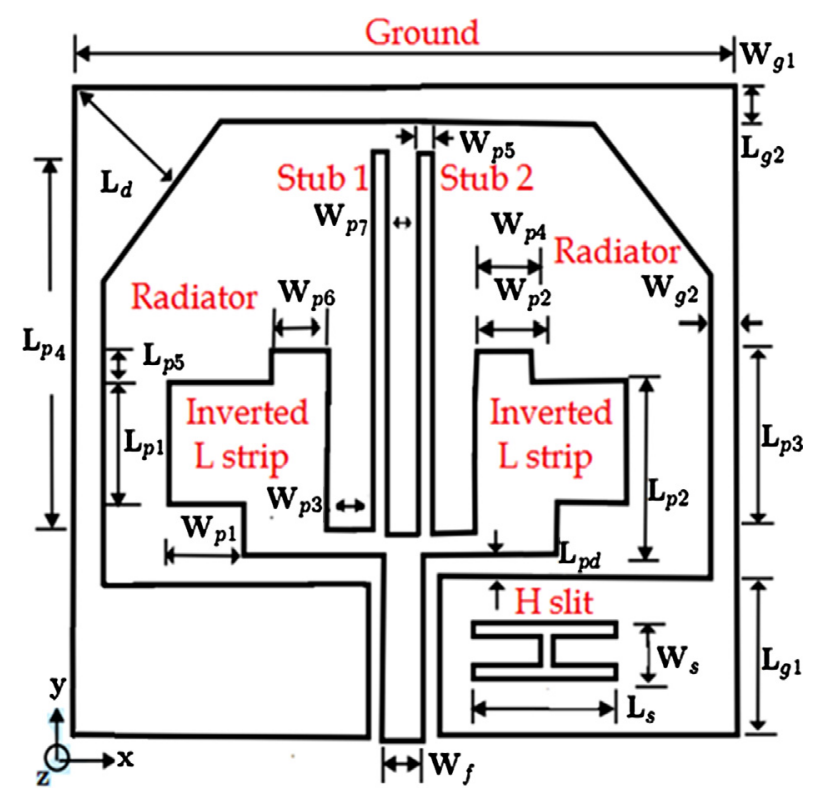

(a) Top view

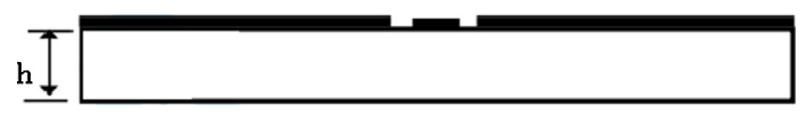

(b) Side view

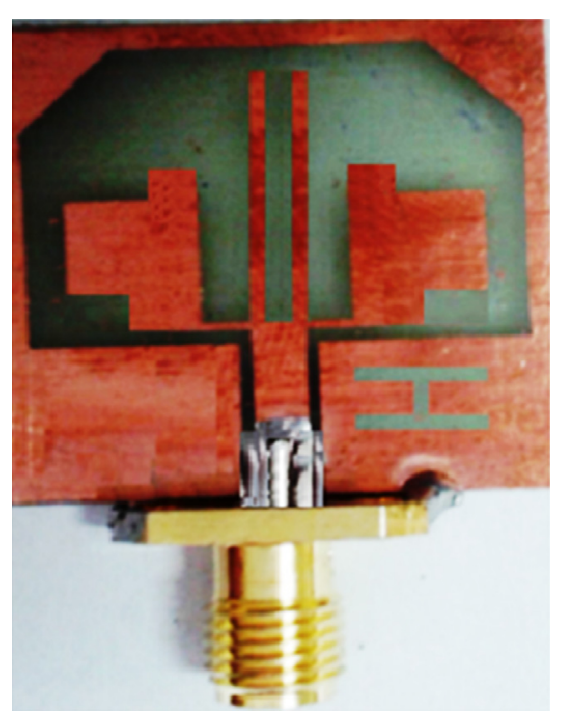

(c) Photograph of the fabricated antenna

Fig. 1. Geometry and photograph of the proposed wideband antenna.

In the above techniques the design of notch bands in antennas is not easy and furthermore the overall size of the resulting antenna is considered to be large to include in wireless transceivers.

In this article we have proposed a novel miniature wideband microstrip antenna design to overcome the above cited limitations in reported wideband antennas, in particular, (i) the proposed antenna design is simple; (ii) it can be fabricated on a single layer of the dielectric substrate; (iii) it avoids the use of via-holes; (iv) is cheaper to fabricate; and (v) it is relatively smaller in size. The proposed antenna includes band-notched functionality that is capable of eliminating interferences from GPS, Bluetooth and WiFi systems. This is achieved by embedding an $\mathrm{H}$-shaped slit, which has been rotated by $90^{\circ}$, in the ground-plane conductor. The function of the slit is to reject interferences between $1574.4 \mathrm{MHz}-$ 1576.4 MHz, $2402 \mathrm{MHz}-2480 \mathrm{MHz}$, and $2412 \mathrm{MHz}-2483.5 \mathrm{MHz}$. Two vertical stubs in close proximity are deployed between the radiation patches to create resonances that extend the antenna's bandwidth for wideband operation from $500 \mathrm{MHz}$ to $3.05 \mathrm{GHz}$ with good radiation performance.

\section{Antenna design with notched bands}

The geometry of the proposed antenna is shown in Fig. 1. The rectangular antenna includes two vertical narrow stubs that are in close proximity located on either side of the square patches. The square radiators and stubs are surrounded by the groundplane conductor. The patches are fed through a common coplanar waveguide (CPW) transmission line. Etched in the ground-plane conductor and located next to the CPW feed-line is an $\mathrm{H}$-shaped slit, which is rotated by $90^{\circ}$. The purpose of the $\mathrm{H}$-shaped slit is to reject the unwanted frequencies at the GPS, Bluetooth and WiFi bands. The bandwidth of the rejection bands can be controlled by simply adjusting the length and width of the $\mathrm{H}$-shaped slit. The two vertical stubs in the antenna are used to create resonances to provide wideband operation from $500 \mathrm{MHz}$ to $3.05 \mathrm{GHz}$ with good radiation performances.

The equivalent circuit of the proposed band-notched wideband antenna is depicted in Fig. 2, where the radiating element is approximately represented by several RLC parallel cells in series. The equivalent circuit input impedance can be expressed as [34]

$Z_{n}=\sum_{k=1}^{n} \frac{j \omega R_{k} L_{k}}{R_{k}\left(1-\omega^{2} C_{k} L_{k}\right)+j \omega L_{k}}$

The antenna was designed and fabricated on a $0.8 \mathrm{~mm}$-thick Rogers RT/Duroid5880 substrate with dielectric constant $\varepsilon_{r}$ of 2.2 and loss tangent of $9 \times 10^{-4}$. The overall dimensions of the antenna are $15 \times 15 \times 0.8 \mathrm{~mm}^{3}$. The antenna's performance was optimized using Ansoft's HFSS [35], a commercial electromagnetic simulator based on finite element method (FEM). The optimized parameters of the antenna are given in Table 1.

The effect of the length and width of $\mathrm{H}$-shaped slit on the antenna's performance was studied. The simulated reflection coefficient response with different values of slit width $\left(W_{s}\right)$ is shown in Fig. 3.

It is evident from Fig. 3 that when $W_{s}$ is increased from 0.5 to $1.5 \mathrm{~mm}$, the first rejection band moves marginally toward the lower frequency, while second rejection band, which is located at the Bluetooth and WiFi frequency range, remains unchanged. The optimum value of $W_{s}=1 \mathrm{~mm}$ was found to provide a notch rejection centered at $1575.4 \mathrm{MHz}$ (GPS band). Fig. 4 shows the simulated reflection coefficient response of the antenna as a function of slit length $\left(L_{S}\right)$ when it's varied from 3.3 to $5.3 \mathrm{~mm}$. The change in slit length causes a marginal change in the second stop-band while the first notch-band at the GPS frequency range remains unaffected. An increase in $L_{s}$ causes the second notch-band to shift towards the higher frequency and increases the magnitude of the rejection level. The slit length selected in the design was $3.3 \mathrm{~mm}$ to provide a notch rejection centered at $2.443 \mathrm{GHz}$ (Bluetooth and WiFi bands).

The current distribution over the antenna without and with the $\mathrm{H}$-shaped slit is shown in Fig. 5. It is observed that the current density is strongly concentrated at the edges of the $\mathrm{H}$-shaped slit corresponding to the center frequency of the first and second notch bands, i.e. $1575.4 \mathrm{MHz}$ and $2443 \mathrm{MHz}$, respectively. At the pass-band frequency of $1700 \mathrm{MHz}$ (outside the notched bands), the distribution of the surface current is uniform over the entire antenna. Clearly the $\mathrm{H}$-shaped slit provides an effective current path to ground for frequencies centered around $1575.4 \mathrm{MHz}$ and 


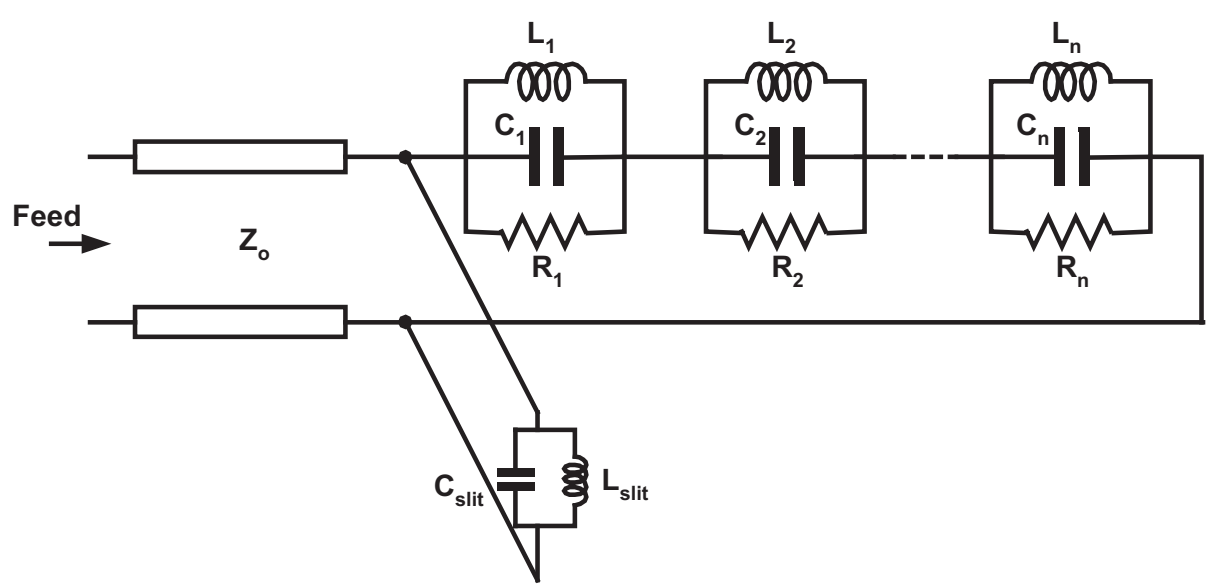

Fig. 2. Impedance model for radiating element of the proposed wideband antenna.

Table 1

Antenna design parameters (units in $\mathrm{mm}$ ).

\begin{tabular}{|c|c|c|c|c|c|}
\hline$L_{p 1}: 3$ & $L_{p 2}: 4.5$ & $L_{p 3}: 4.6$ & $L_{p 4}: 9$ & $L_{p 5}: 1$ & $L_{p d}: 0.35$ \\
\hline$L_{s}: 3.3$ & $W_{p 1}: 2.15$ & $W_{p 2}: 1.9$ & $W_{p 3}: 1.3$ & $W_{p 4}: 1.3$ & $W_{p 5}: 0.5$ \\
\hline$W_{p 6}: 1.3$ & $W_{p 7}: 1$ & $W_{s}: 1$ & $L_{\mathrm{g} 1}: 3.8$ & $L_{\mathrm{g} 2}: 0.8$ & $L_{d}: 2.4$ \\
\hline$W_{g 1}: 15$ & $W_{\mathrm{g} 2}: 0.9$ & $W_{f}: 1.5$ & $h: 0.8$ & & \\
\hline
\end{tabular}

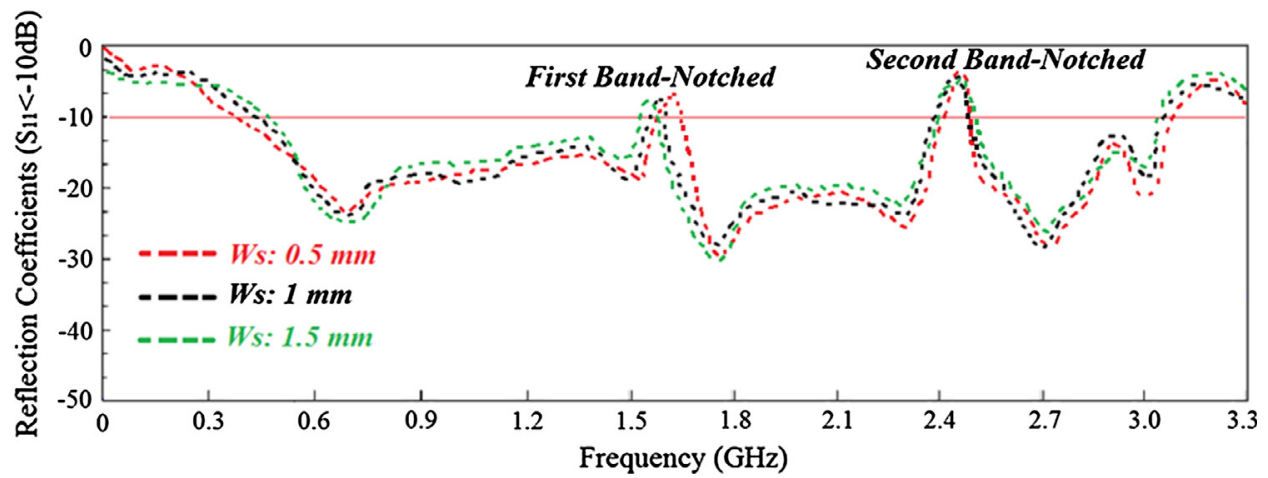

Fig. 3. Simulated reflection coefficient response of the proposed antenna as a function of $W_{s}$. All other parameters are the same as listed in Table 1 .

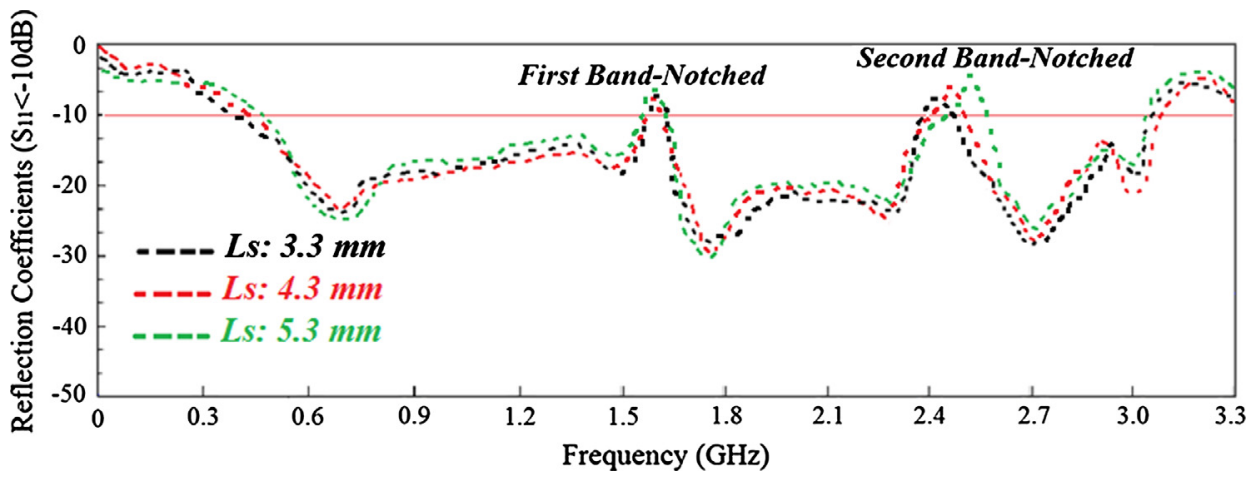

Fig. 4. Simulated reflection coefficient response of the proposed antenna as a function of $L_{s}$. All other parameters are the same as listed in Table 1 .

$2443 \mathrm{MHz}$, which is necessary to eliminate interference from GPS, Bluetooth and WiFi systems.

\section{Results and discussions}

Fig. 6 shows simulated and measured reflection coefficient of the proposed antenna. Measurement was performed with an
Agilent N5230A vector network analyzer. There is good agreement between the simulated and measured results, which show that the antenna operates across $0.5-3.05 \mathrm{GHz}$ for a VSWR less than 2, exhibiting two distinct notch bands between $1574.4 \mathrm{MHz}-$ 1576.4 MHz and $2402 \mathrm{MHz}-2484 \mathrm{MHz}$.

The simulated and measured radiation patterns of proposed antenna without and with H-shaped slit in the E-plane $(x-y)$ and 


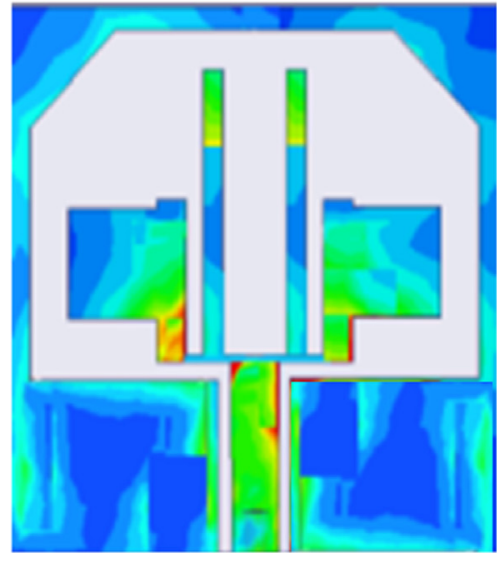

At $1575.4 \mathrm{MHz}$

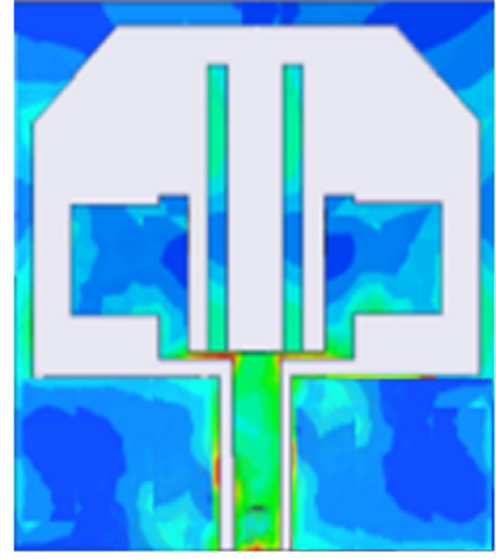

At $2443 \mathrm{MHz}$

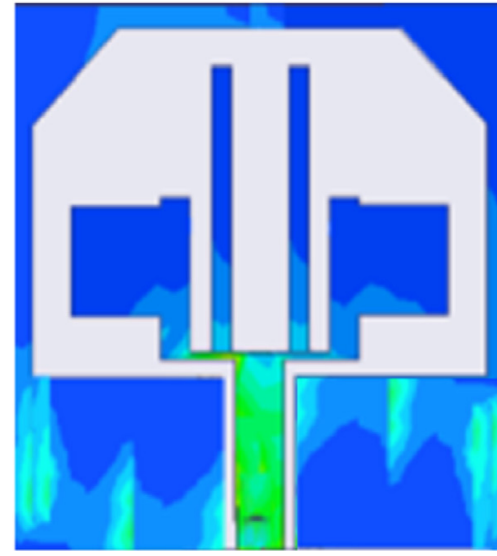

At $1700 \mathrm{MHz}$

(a) Proposed antenna without H-shaped slit

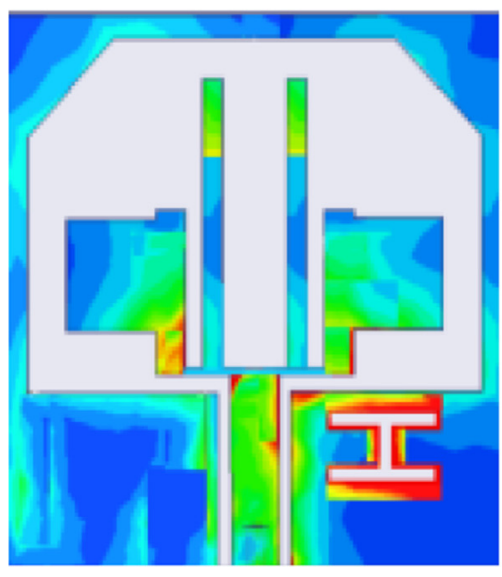

At $1575.4 \mathrm{MHz}$

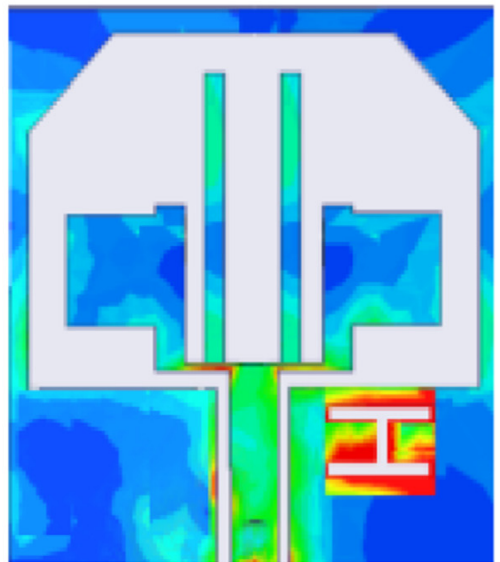

At $2443 \mathrm{MHz}$

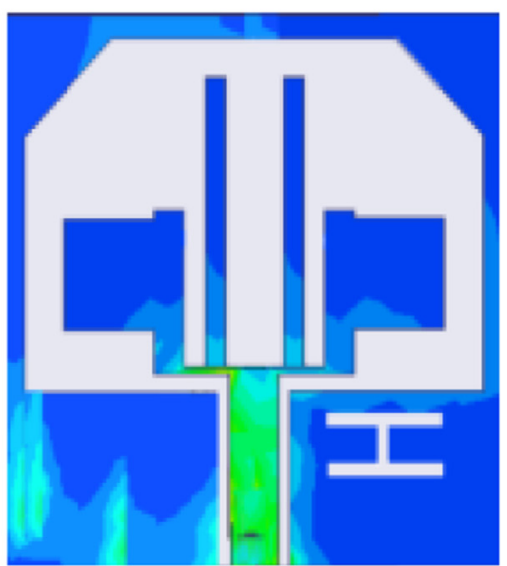

At $1700 \mathrm{MHz}$

Jsurf[A_per_n]

(b) Proposed antenna with $\mathrm{H}$-shaped slit

Fig. 5. Surface current densities over the proposed antenna at various frequencies, (a) without H-shaped slit, and (b) with H-shaped slit.

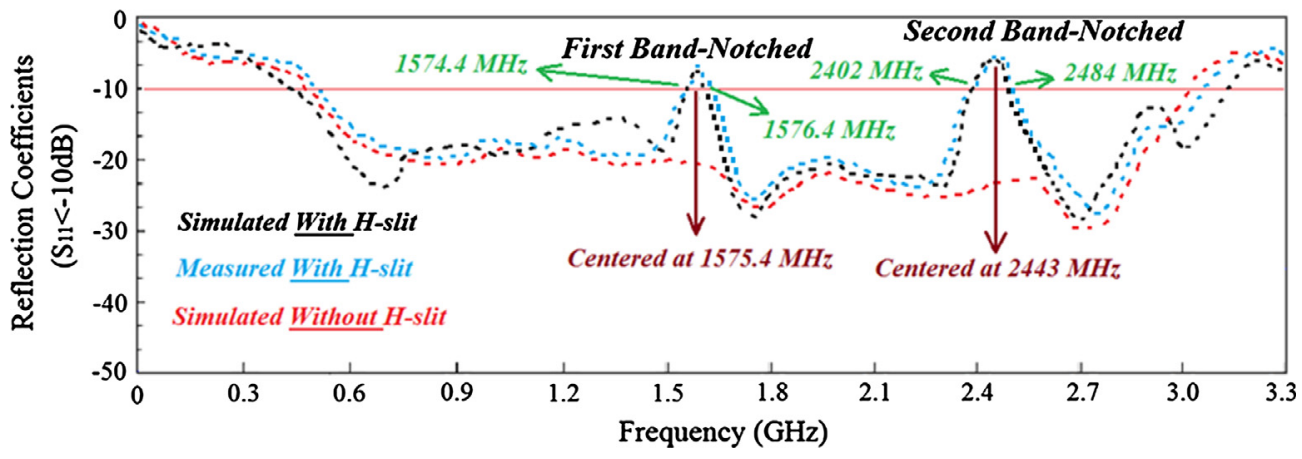

Fig. 6. Simulated and measured reflection coefficient of the proposed wideband antenna with two notch bands.

H-plane $(x-z)$ at $1575.4 \mathrm{MHz}, 2443 \mathrm{MHz}$, and $1700 \mathrm{MHz}$ are shown in Figs. 7 and 8. The co- and cross-polarizations in the E-plane of the antenna excluding the $\mathrm{H}$-shaped slit are shown by the red and green lines, respectively, in Fig. 7; and the co- and crosspolarizations in the H-plane are shown by blue and black lines, respectively. At the two notched band frequencies centered at
1575.4 MHz and $2443 \mathrm{MHz}$ the antenna radiation is omnidirectional; however at $1700 \mathrm{MHz}$ the antenna's radiation patterns in E- and H-planes are dipole-like.

The antenna with H-shaped slit, shown in Fig. 8, radiates omnidirectionally in the E-plane and has dipole-like radiation pattern in the $\mathrm{H}$-plane at frequencies outside the notched bands. The 


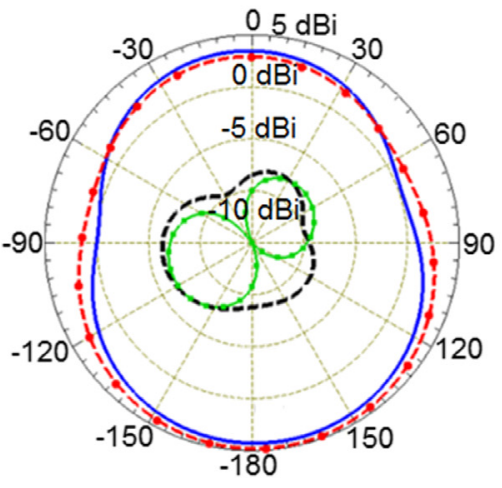

At $1575.4 \mathrm{MHz}$

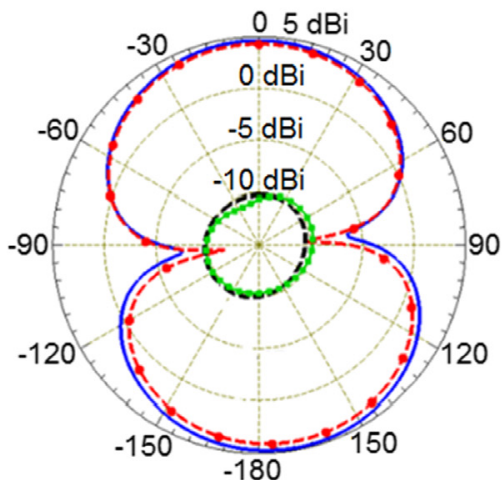

At $1700 \mathrm{MHz}$

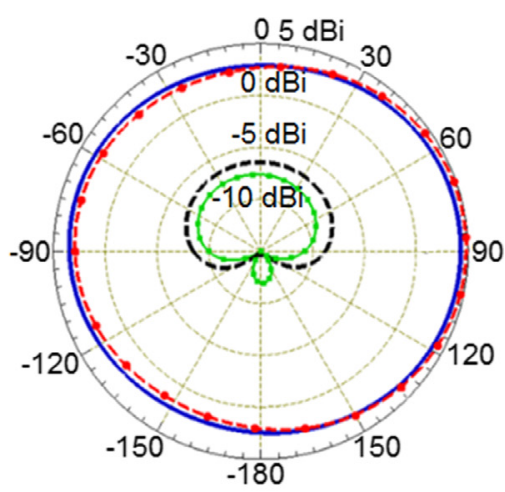

At $2443 \mathrm{MHz}$

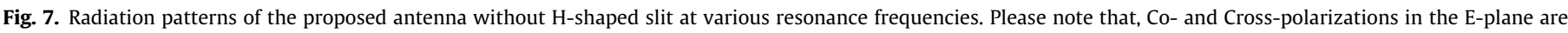

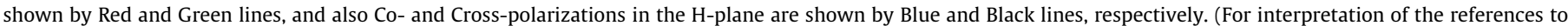
color in this figure legend, the reader is referred to the web version of this article.)
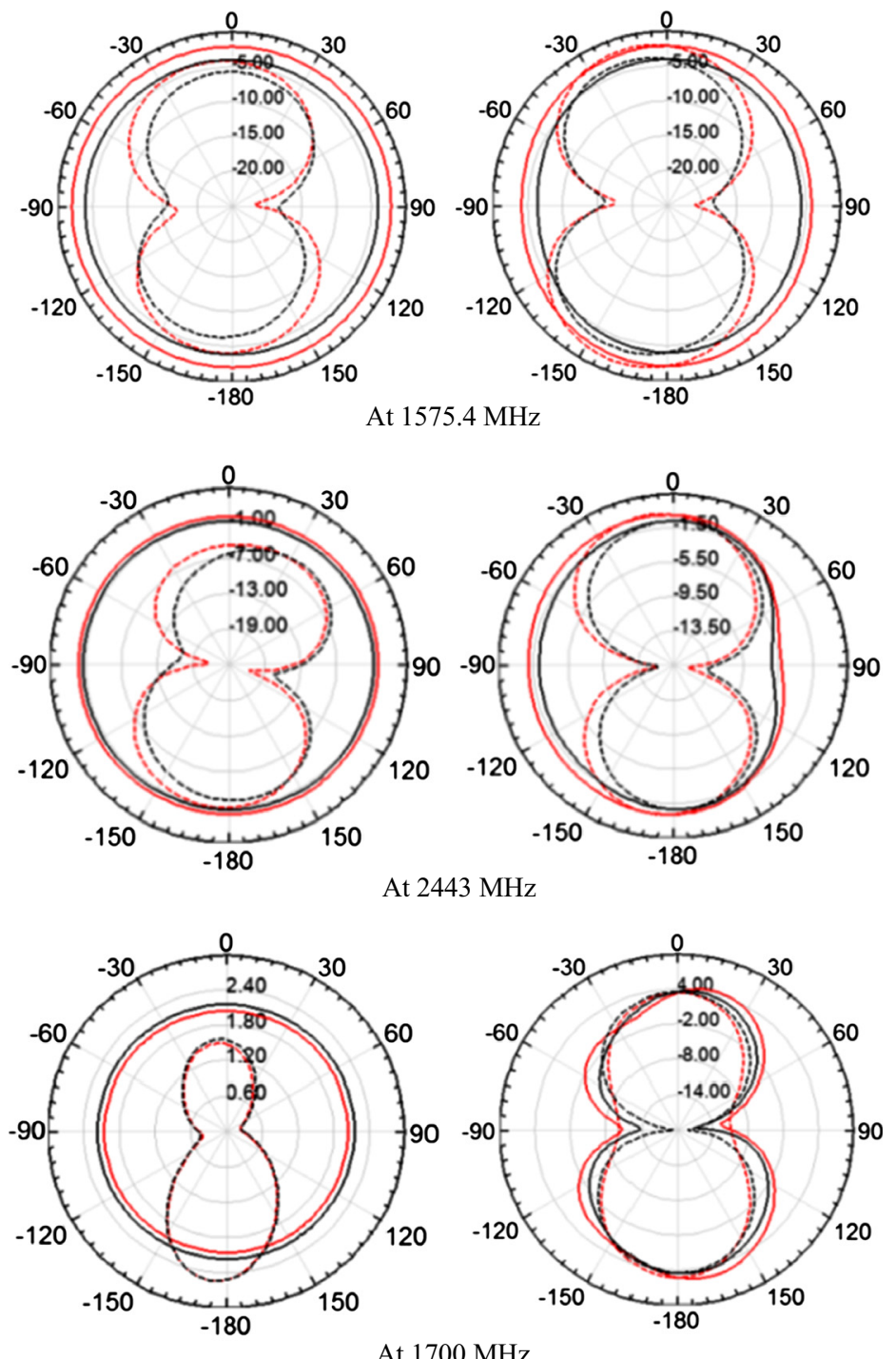

$E(x y)$-plane

At $1700 \mathrm{MHz}$

-Simulated-Measured

$\mathrm{H}(\mathrm{xz})$-plane

-co-polar--- cross-polar

Fig. 8. Radiation patterns of the proposed antenna at various resonance frequencies. 


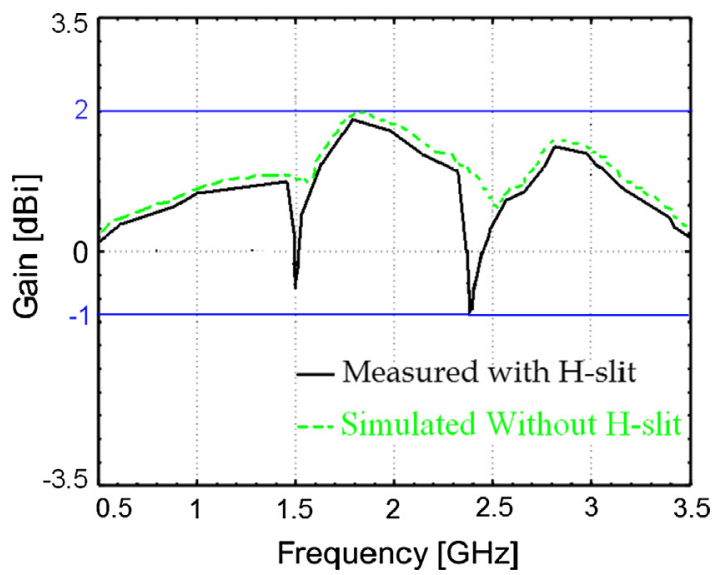

Fig. 9. The simulated and measured gain response of the proposed antenna with and without band-notches.

Table 2

Antenna characteristics.

Dimension $\left(\mathrm{mm}^{3}\right)$

Bandwidth $(\mathrm{GHz})$

Gain (dBi) @ freq. (GHz): 0.5, 1,

$1.5754,1.7,2.443,2.8$ and 3.05

Efficiency (\%)@ same frequencies

$15 \times 15 \times 0.8$

$2.55 \mathrm{GHz}$ (from $0.5 \mathrm{GHz}$ to $3.05 \mathrm{GHz}$ ) band-notches between $1574.4 \mathrm{GHz}-$ $1576.4 \mathrm{GHz}$ and $2402 \mathrm{GHz}-2484 \mathrm{GHz}$ $0.1,0.8,-0.5,1.9,-1.0,1.2$ and 0.9

$15,28,10,52,13,48$ and 36

antenna's radiation patterns are stable at the notched band frequencies centered at $1575.4 \mathrm{MHz}$ and $2443 \mathrm{MHz}$, shown in Fig. 8 (a) and (b). At these two frequencies the antenna gain drops significantly, as depicted in Fig. 9. The resulting antenna characteristics are summarized in Table 2.

The antenna efficiency was measured in an anechoic chamber by feeding power to the antenna feed and measuring the strength of the radiated electromagnetic field in the surrounding space. The efficiency was calculated by taking the ratio of the radiated power to the input power of the antenna. The gain of the antenna was measured using the standard gain comparison technique where pre-calibrated standard gain antenna was used to determine the absolute gain of the antenna under test.

\section{Conclusions}

Results of a novel miniature wideband printed microstrip antenna are presented that exhibits dual notched band property enabling mitigation of interference from GPS, Bluetooth and WiFi bands. The antenna employs two radiating patches separated with two vertical open-circuited stubs to provide wideband operation from $500 \mathrm{MHz}$ to $3.05 \mathrm{GHz}$. Also included is an $\mathrm{H}$-shaped slit, rotated by $90^{\circ}$, etched in the ground-plane conductor whose function is to reject interferences between bands $1574.4 \mathrm{MHz}-$ 1576.4 MHz, $2402 \mathrm{MHz}-2480 \mathrm{MHz}$, and $2412 \mathrm{MHz}-2483.5 \mathrm{MHz}$. The antenna performance is stable over its operating frequency range and it radiates omnidirectionally in the E-plane. The proposed antenna is suitable for integration in portable wireless systems.

\section{References}

[1] Barrios EL, Ursua A, Marroyo L, Sanchis P. Analytical design methodology for Litz-wired high-frequency power transformers. IEEE Trans Ind Electron 2015;62(4):2103-13.

[2] Ju X, Dong L, Huang X, Liao X. Switching technique for inductive power transfer at high-Q regimes. IEEE Trans Ind Electron 2015;62(4):2164-73.
[3] Jedidi A, Garrab H, Morel H, Besbes K. A novel approach to extract the thyristor design parameters for designing of power electronic systems. IEEE Trans Ind Electron 2015;62(4):2174-83.

[4] Alibakhshi-Kenari M, Naser-Moghadasi M, Sadeghzadah RA. Bandwidth and radiation specifications enhancement of monopole antennas loaded with split ring resonators. IET Microw Antennas Propag 2015;9(14):1487-96.

[5] Ahmed O, Sebak AR. A printed monopole antenna with two steps and a circular slot for UWB applications. IEEE Antenna Wirel Propag Lett 2008;7 411-3.

[6] Alibakhshi-Kenari M, Naser-Moghadasi M. Novel UWB miniaturized integrated antenna based on CRLH metamaterial transmission lines. AEUE - Int J Electron Commun 2015;69(8):1143-9.

[7] Azim R, Islam MT, Misran N. Compact tapered shape slot antenna for UWB applications. IEEE Antenna Wirel Propag Lett 2011;10:1190-3.

[8] Verbiest JR, Vandenbosch GAE. A novel small-size printed tapered monopole antenna for UWB WLAN. IEEE Antennas Wirel Propag Lett 2006:5:377-9.

[9] Alibakhshi-Kenari M, Naser-Moghadasi M, Sadeghzadeh RA. Composite rightleft-handed-based antenna with wide applications in very-high frequencyultra-high frequency bands for radio transceivers. IET Microw Antennas Propag 2015;9(15):1713-26.

[10] Radiom S, Aliakbarian H, Vandenbosch GAE, Gielen GGE. An effective technique for symmetric planar monopole antenna miniaturization. IEEE Trans Antennas Propag 2009;57:2989-96.

[11] Alibakhshi-Kenari M, Naser-Moghadasi M, Sadeghzadah RA. The resonating MTM based miniaturized antennas for wide-band RF-microwave systems. Microw Opt Technol Lett 2015;57(10):2339-44.

[12] Valderas D, Alvarez R, Melendez J, Gurutzeaga I, Legarda J, Sancho JI. UWB staircase-profile printed monopole design. IEEE Antennas Wirel Propag Lett 2008; $7: 255-9$.

[13] Alibakhshi-Kenari M, Naser-Moghadasi M, Virdee BS, Andújar A, Anguera J. Compact antenna based on a composite right/left handed transmission line. Microw Opt Technol Lett 2015;57(8):1785-8.

[14] Alibakhshi-Kenari M. Introducing the new wideband small plate antennas with engraved voids to form new geometries based on CRLH MTM-TLs for wireless applications. Int J Microw Wirel Technol 2014;6(6):629-37.

[15] Islam MM, Faruque MRI, Islam MT. A compact $5.5 \mathrm{GHz}$ band-rejected UWB antenna using complementary split ring resonator. Sci World J 2014:1-8 [Article ID 528489].

[16] Islam MM, Islam MT, Samsuzzaman M, Faruque MRI. Five band-notched ultrawideband (UWB) antenna loaded with C-shaped slots. Microw Opt Technol Lett 2015:57(6):1470-5.

[17] Zhang Y, Hong W, Yu C, Kuai ZQ, Don YD, Zhou JY. Planar ultra wideband antennas with multiple notched bands based on etched slots on the patch and or split ring resonators on the feed line. IEEE Trans Antenna Propag 2008;56:3063-8.

[18] Ma TG, Wu SJ. Ultra wideband band-notched folded strip monopole antenna. IEEE Trans Antenna Propag 2007:55:2473-9.

[19] Hong CY, Ling CW, Tarn IY, Chung SJ. Design of a planar ultra wideband antenna with a new band-notch structure. IEEE Trans Antennas Propag 2007;55(12):3391-7.

[20] Wong KL, Chi YW, Su CM, Chang FS. Band-notched ultra-wideband circulardisk monopole antenna with an arc-shaped slot. Microw Opt Tech Lett 2005;45:188-91.

[21] Huang CY, Hsia WC. Planar ultra-wideband antenna with a frequency notch characteristic. Microw Opt Technol Lett 2007;49:316-20.

[22] Jang JW, Hwang HY. An improved band-rejection UWB antenna with resonant patches and a slot. IEEE Antennas Wirel Propag Lett 2009;8:299-302.

[23] Nguyen DT, Lee DH, Park HC. Very compact printed triple band-notched UWB antenna with quarter-wavelength slots. IEEE Antennas Wirel Propag Lett 2012;11:411-4.

[24] Zaker R, Ghobadi C, Nourinia J. Bandwidth enhancement of novel compact single and dual band-notched printed monopole antenna with a pair of Lshaped slots. IEEE Trans Antennas Propag 2009;57(12):3978-83.

[25] Lee WS, Kim DZ, Kim KJ, Yu JW. Wideband planar monopole antennas with dual band-notched characteristics. IEEE Trans Microw Theory Tech 2006;54:2800-6.

[26] Chu QX, Yang YY. A compact ultrawideband antenna with 3.4/5.5 GHz dual band-notched characteristics. IEEE Trans Antennas Propag 2008;56 (12):3637-44.

[27] Cai LY, Li Y, Zeng G, Yang HC. Compact wideband antenna with double-fed structure having band-notched characteristics. Electron Lett 2010;46 (23):1534-6.

[28] Deng JY, Yin YZ, Zhou SG, Liu QZ. Compact ultra-wideband antenna with triband notched characteristic. Electron Lett 2008;44(21):1231-3.

[29] Tang MC, Xiao S, Deng T, Wang D, Guan J, Wang B, et al. Compact UWB antenna with multiple band-notches for WiMAX and WLAN. IEEE Trans Microw Theory Tech 2011;59(4):1372-6.

[30] Liao XJ, Yang HC, Han N, Li Y. Aperture UWB antenna with triple band-notched characteristics. Electron Lett 2011:47(2):77-9.

[31] Yu C, Hong W, Chiu L, Zhai G, Yu C, Qin W, et al. Ultrawideband printed logperiodic dipole antenna with multiple notched bands. IEEE Trans Antennas Propag 2011:59:725-32.

[32] Rahmati B, Hassani HR. Wideband planar plate monopole antenna with dual tunable notch. Electron. Lett. 2010;46(7):480-1.

[33] Rahmati B, Hassani HR. Multi-notch slot loaded wide band planar plate monopole antenna. IET Microw Antennas Propag 2010;4(12):2160-5. 
[34] Yu F, Wang C. Design of a CPW-fed dual band-notched planar wideband antenna for UWB applications. InTechOpen; 2011.

[35] Ansoft. HFSS simulator version 13.0

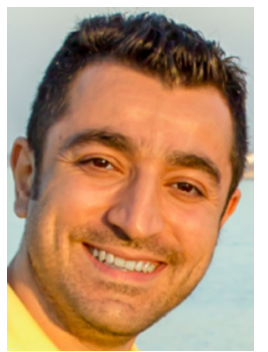

Mohammad Alibakhshikenari received the B.Sc. (February 2010) and M.Sc. (February 2013) degrees in Electrical Engineering and Telecommunication from the Islamic Azad University, Najafabad Branch of Esfahan, Iran and Shahid Bahonar University of Kerman, Iran, respectively. His research interests include microwave and millimeter-wave circuits, transceivers, antennas and wave-propagation, CRLH-TLs, metamaterials, integrated RF-technologies, embedded systems, electromagnetic-waves applications and wireless telecommunication systems. The above research lines have produced more than 20 publications on refereedinternational journals and presentations within international-conferences. Also, his Master Thesis entitled "Designing and Fabricating an Ultra Compact and UWB Antennas based on CRLH Metamaterial Transmission Lines with Application in Wireless Radio Transceivers" was approved and granted by Iran Telecommunication Research Center (ITRC) on December 2012 with grant number of 6987/500/T. He is now "Editor-in-Chief" in Journal Club for Electronic and Communication Engineering and member of the Applied Computational Electromagnetics Society (ACES). He is also a reviewer for several journals including IEEE TIE, IET MAP, IEEE PTL, JIMTW, OSA journals, Wiley journals, Elsevier journals, Taylor \& Francis journals, Springer journals and ACES. He had served as a Member of the Technical Program Committee (M-TPC) at the several IEEE international conferences.

$\mathrm{He}$ is now postgraduate studying in the university of Roma "Tor Vergata" as a PhD student. He works in the Microwave Engineering Center for Space Applications (MECSA) as a R\&D researcher. The head of MECSA is Prof. Ernesto Limiti.

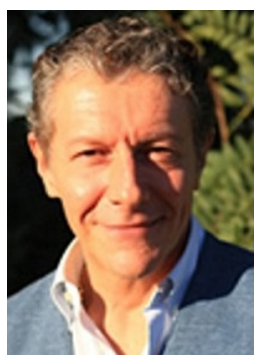

Ernesto Limiti is a full professor of Electronics in the Engineering Faculty of the University of Roma Tor Vergata since 2002, after being research and teaching assistant (since 1991) and associate professor (since 1998 ) in the same University. His research activity is focused on three main lines, all of them belonging to the microwave and millimetre-wave electronics area. The first one is related to characterisation and modelling for active and passive microwave and millimetre-wave devices. Regarding active devices, the research line is oriented to the small-signal, noise and large signal modelling as well as devices on diamond substrates. Novel methodologies have been developed and equivalent-circuit modelling strategies have been implemented both for small and large-signal operating regimes for different device technologies. Design methodologies and characterisation methods for low noise devices and circuits are also in focus, as well as the analysis and design methodologies for linear and nonlinear microwave circuits. The above research lines have produced more than 300 publications on refereed international journals and presentations within international conferences. Ernesto Limiti acts as a referee of international journals of the microwave and millimetre wave electronics sector and he is in the steering committee of international conferences and workshops.

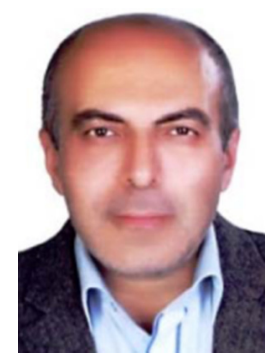

Mohammad Naser-Moghadasi was born in Iran, in 1959. He received the B.Sc. degree in Communication Eng. in 1985 from the Leeds Metropolitan University (formerly Leeds Polytechnic)-UK. Between 1985-1987 he worked as an RF-design-engineer for the Gigatech company in Newcastle Upon Tyne-UK. From 1987 to 1989, he was awarded a full scholarship by the Leeds Educational Authority to pursue an M.Phil. on Studying CAD of microwave-circuits. He received his Ph.D. in 1993, from the University of Bradford-UK. He was offered then a two-years post-doc. at the University of Nottingham-UK, to pursue research on microwave cooking of materials. From 1995, Dr. Naser-Moghadasi joined Islamic Azad University, Science and Research Branch, Iran-Tehran, where he currently is head of postgraduate studies. His main areas of interest in research are microstrip antenna, microwave passive and active circuits, RF MEMS. Dr. Naser-Moghadasi is member of the IET, MIET and IEICE. He has so far published over 150 papers.

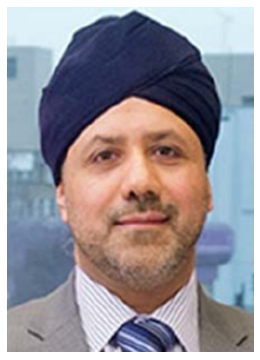

Bal Singh Virdee received the B.Sc. and MPhil degrees in Communications-Engineering from the University of Leeds-UK and his Ph.D. in Electronic-Engineering from the University of London-UK. He has worked in industry for various companies including Philips (UK) as an R\&Dengineer and Filtronic-Components Ltd. as a future products developer in the area of $\mathrm{RF} /$ microwave communications. He has taught at several academic institutions before joining London Metropolitan University where he is a Professor of Microwave-Communications in the Faculty of Life Sciences\&Computing where he Heads the Center for Communications-Technology and is the Director of London Metropolitan-Microwaves. His research, in collaboration with industry and academia, is in the area of microwave wireless communications encompassing mobile-phones to satellite-technology. Prof. Virdee has chaired technical sessions at IEEE international conferences and published numerous research-papers. He is Executive-Member of IET's Technical and Professional Network Committee on RF/Microwave-Technology. He is a Fellow of IET and a SeniorMember of IEEE.

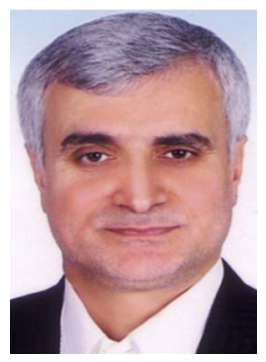

Professor R.A. Sadeghzadeh is a full professor of communications Engineering at the faculty of Electrical Engineering of the K.N. Toosi University of Technology. He received his B.Sc. in 1984 in telecommunications Engineering from the K.N. Toosi, University of Technology in Tehran, Iran, and M.Sc. in digital Communications Engineering from the University of Bradford and UMIST (University of Manchester Institute of Science and Technology), UK as a joint program in 1987. He received his Ph.D. in electromagnetic and antenna from the University of Bradford, UK in 1990. He worked as a PostDoctoral Research assistant in the field of propagation, electromagnetic, antenna, Bio-Medical, and Wireless communications from 1990 till 1997. From 1984 to 1985 he was with Telecommunication Company of Iran (TCI) working on Networking. Since 1997 he is with the K.N. Toosi University of Technology working with Telecommunications Dept. at the faculty of Electrical Engineering. He has published more than 175 referable papers in international journals and conferences. Professor Sadeghzadeh current interests are numerical techniques in electromagnetic, antenna, propagation, radio networks, wireless communications, nano-antennas and radar systems. 